NASA/TM-2004-213107

\title{
Parametric Testing of Chevrons on Single Flow Hot Jets
}

James Bridges and Clifford A. Brown

Glenn Research Center, Cleveland, Ohio 
Since its founding, NASA has been dedicated to the advancement of aeronautics and space science. The NASA Scientific and Technical Information (STI) Program Office plays a key part in helping NASA maintain this important role.

The NASA STI Program Office is operated by Langley Research Center, the Lead Center for NASA's scientific and technical information. The NASA STI Program Office provides access to the NASA STI Database, the largest collection of aeronautical and space science STI in the world. The Program Office is also NASA's institutional mechanism for disseminating the results of its research and development activities. These results are published by NASA in the NASA STI Report Series, which includes the following report types:

- TECHNICAL PUBLICATION. Reports of completed research or a major significant phase of research that present the results of NASA programs and include extensive data or theoretical analysis. Includes compilations of significant scientific and technical data and information deemed to be of continuing reference value. NASA's counterpart of peerreviewed formal professional papers but has less stringent limitations on manuscript length and extent of graphic presentations.

- TECHNICAL MEMORANDUM. Scientific and technical findings that are preliminary or of specialized interest, e.g., quick release reports, working papers, and bibliographies that contain minimal annotation. Does not contain extensive analysis.

- CONTRACTOR REPORT. Scientific and technical findings by NASA-sponsored contractors and grantees.
- CONFERENCE PUBLICATION. Collected papers from scientific and technical conferences, symposia, seminars, or other meetings sponsored or cosponsored by NASA.

- SPECIAL PUBLICATION. Scientific, technical, or historical information from NASA programs, projects, and missions, often concerned with subjects having substantial public interest.

- TECHNICAL TRANSLATION. Englishlanguage translations of foreign scientific and technical material pertinent to NASA's mission.

Specialized services that complement the STI Program Office's diverse offerings include creating custom thesauri, building customized databases, organizing and publishing research results ... even providing videos.

For more information about the NASA STI Program Office, see the following:

- Access the NASA STI Program Home Page at http://www.sti.nasa.gov

- E-mail your question via the Internet to help@sti.nasa.gov

- Fax your question to the NASA Access Help Desk at 301-621-0134

- Telephone the NASA Access Help Desk at 301-621-0390

- Write to:

NASA Access Help Desk

NASA Center for AeroSpace Information 7121 Standard Drive

Hanover, MD 21076 
NASA/TM-2004-213107

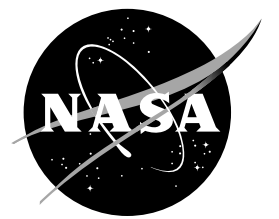

\section{Parametric Testing of Chevrons on Single Flow Hot Jets}

James Bridges and Clifford A. Brown

Glenn Research Center, Cleveland, Ohio

Prepared for the

Tenth Aeroacoustics Conference

cosponsored by the American Institute of Aeronautics and Astronautics and the Confederation of European Aerospace Societies

Manchester, United Kingdom, May 10-12, 2004

National Aeronautics and

Space Administration

Glenn Research Center 
Available from

NASA Center for Aerospace Information 7121 Standard Drive

Hanover, MD 21076
National Technical Information Service 5285 Port Royal Road Springfield, VA 22100

Available electronically at http://gltrs.grc.nasa.gov 


\title{
Parametric Testing of Chevrons on Single Flow Hot Jets
}

\author{
James Bridges and Clifford A. Brown \\ National Aeronautics and Space Administration \\ Glenn Research Center \\ Cleveland, Ohio 44135
}

\begin{abstract}
Summary
A parametric family of chevron nozzles have been studied, looking for relationships between chevron geometric parameters, flow characteristics, and far-field noise. Both cold and hot conditions have been run at acoustic Mach number 0.9. Ten models have been tested, varying chevron count, penetration, length, and chevron symmetry. Four comparative studies were defined from these datasets which show: that chevron length is not a major impact on either flow or sound; that chevron penetration increases noise at high frequency and lowers it at low frequency, especially for low chevron counts; that chevron count is a strong player with good low frequency reductions being achieved with high chevron count without strong high frequency penalty; and that chevron asymmetry slightly reduces the impact of the chevron. Finally, it is shown that although the hot jets differ systematically from the cold one, the overall trends with chevron parameters is the same.
\end{abstract}

\section{Nomenclature}

D baseline nozzle diameter

$\mathrm{D}_{\mathrm{e}} \quad$ equivalent weight flow jet diameter

$\Gamma \quad$ vortex strength parameter

$\mathrm{L} \quad$ chevron length

$\mathrm{N} \quad$ number of chevrons on nozzle

\section{Motivation}

The idea of using mixing enhancement to reduce jet noise is not new. Lobed mixers have been around since shortly after jet noise became a problem. However, our understanding of their impact on jet noise is still not in hand. Although one view is that the enhanced mixing lowers the effective jet velocity in the main noise-producing region of the jet, it also greatly reduces the turbulence there while increasing it near the nozzle. This leads to the classic trade-off between low frequency reduction and high frequency penalty from the enhanced mixing. More understanding of how these devices impact jet noise, preferably reducing the high frequency penalty, and perhaps extending to the point of developing a physics-based noise prediction code is the ultimate goal of the research program whose initial tests are described here.

Having first studied the impact of chevrons on separate flow nozzles, ${ }^{1,2}$ we have recently turned to studying chevrons on single flow nozzles in a small hot jet rig. This has allowed us to better explore the relationships between geometry, flow, and far-field acoustics, providing good test cases for developing robust noise prediction codes, and hopefully leading to better ideas for noise reduction. Several chevron nozzles were designed to parametrically vary characteristics that seem important to the flow and noise field: number of chevrons (varying the spacing of axial vorticity), chevron penetration (varying the strength of the axial vorticity), and chevron length (varying the distribution of the vorticity within the axial vortices). These designs were made easy to fabricate and completely describe, not optimized for 
performance or acoustics, intended solely for their ability to evaluate relative impacts of chevron parameters on single-stream static jet flows. Far-field noise measurements and plume survey measurements were made, with cross-stream stereo PIV used to acquire mean and turbulent velocities on a limited number of cases.

This paper is organized as follows: a section describing the test hardware and instrumentation systems, a section presenting raw data for the different chevron nozzles, and then several sections where particular parametric variations in chevron design are isolated and evaluated.

\section{Test Hardware and Instrumentation}

\section{Jet Rig}

The parametric chevron tests were conducted on the Small Hot Jet Acoustic Rig (SHJAR) located within the AeroAcoustic Propulsion Lab (AAPL) at NASA Glenn Research Center. The rig provided single-flow jet models with heated air up to $850{ }^{\circ} \mathrm{F}$ using a hydrogen combustor. Flow conditioning and a line-of-sight muffler created a very clean, quiet flow in the large anechoic Lab. More details on the SHJAR are found in reference 3. Internal rig noise from valves, screens, etc. were separated and measured by using several size nozzles (including no nozzle) and correlating spectra with mass flow rate. For the $51 \mathrm{~mm}$ nominal nozzle diameter of the current study, the rig noise is $6 \mathrm{~dB}$ below all spectral points for $\mathrm{M}>0.35$.

For consistency with the growing NASA jet noise database, data were acquired on a subset of flow conditions defined by Tanna ${ }^{4}$ for hot jets. For brevity, only two conditions, setpoints 7 and 46, approximately $\mathrm{M}_{\infty}=\mathrm{U}_{\mathrm{j}} / \mathrm{c}_{\mathrm{j}}=0.9$ at static temperature ratio $\mathrm{T}_{\mathrm{s}} / \mathrm{T}_{\infty}=0.86$ and 2.7 respectively are presented here. By comparing the effect of chevron parameters on these two setpoints, the importance of thermal energy on the chevron phenomena can be established.

\section{Models}

The nozzles tested were designed with a parametric scheme in mind. Simplistically, chevrons on nozzles produce axial vorticity that increases cross-stream transport and mixing in the shear layer of the potential core. It has been observed that when the axial vorticity generated by the chevrons is closely spaced, the vortices tend to annihilate one another quickly, limiting the cross-stream transport they accomplish. It seems logical that the stronger the axial vorticity the more transport and mixing they will accomplish, and it would seem reasonable that details of the distribution of the vorticity within the vortex core would impact the stability of the vortex. Therefore, the main flow field parameters to vary were vortex strength, vortex spacing, and vorticity distribution. These seem to be correlated with the nozzle geometry features of chevron penetration, chevron count, and chevron length, respectively. Lacking CFD capabilities to quickly validate designs, a series of nozzles were created with different combinations of number of chevrons $\mathrm{N}$, penetrations (given by angle to jet centerline), and length, holding features constant and systematically varying others. In addition, chevron symmetry was considered with one side of the chevrons were nearly straight, with the effect that the nozzle looks like a hole saw. One nozzle was left without chevrons as baseline configuration (SMC000). The result is the collection of 11 nozzles shown in figure 1 and described in table 1. The Nozzle IDs used in this report are not meant to be acronyms, but simply as serial numbers. The nozzles shown in the photographs were mounted on a contraction which started at a $150 \mathrm{~mm}$ diameter inlet pipe and contracted sharply before rounding out to the final $5^{\circ}$ taper (figure 2). 


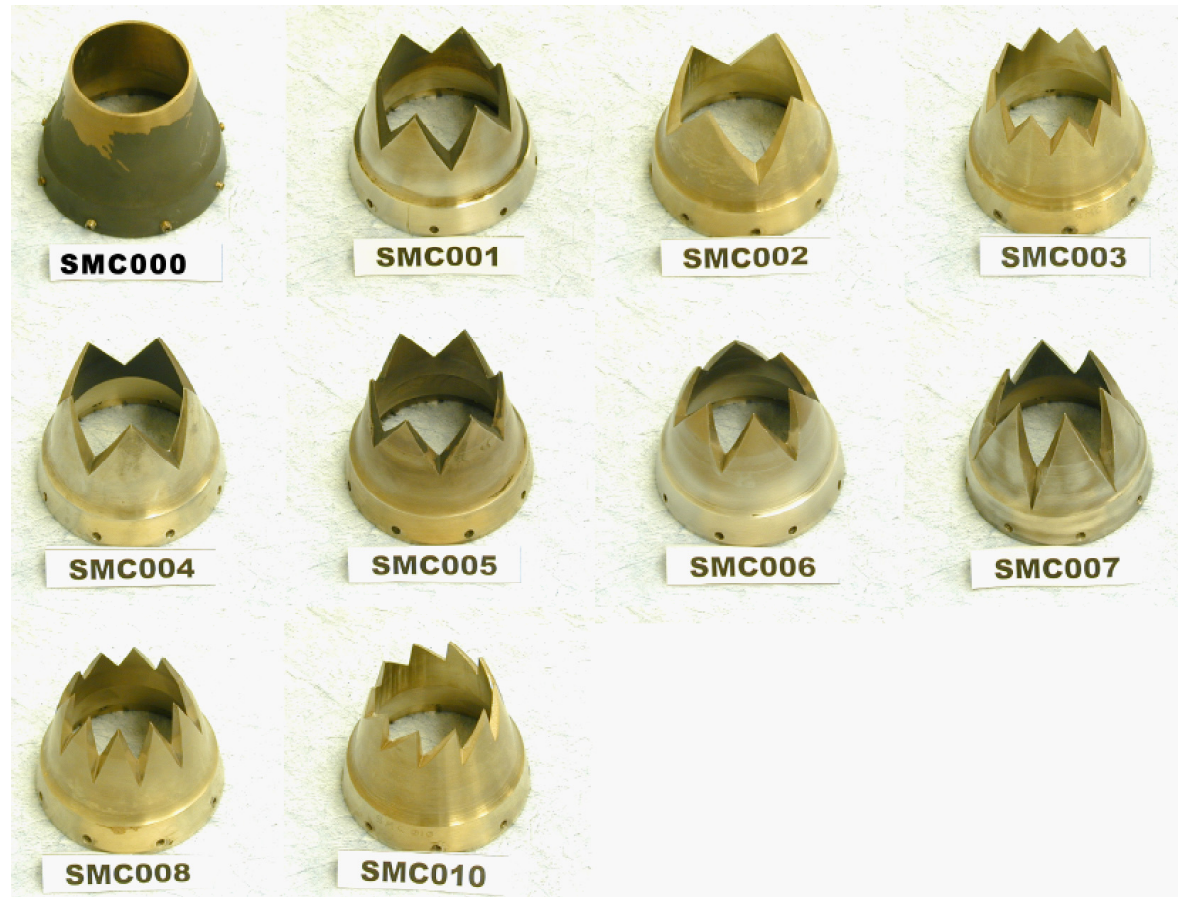

Figure 1.-Pictures of chevron nozzles used in study, identified by serial number.

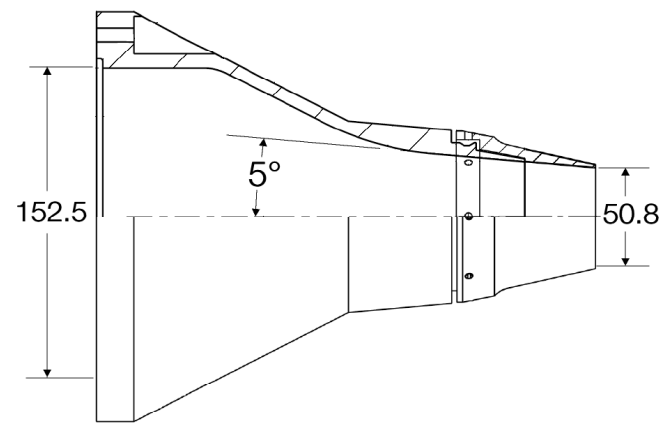

Figure 2.-Overall nozzle showing mounting scheme for different chevron nozzle end pieces. Linear dimensions are in $\mathrm{mm}$.

In table $1, \mathrm{~N}$ was the number of chevrons and Length was the length of the chevrons along the jet axis. Angle was the deviation of the chevron from the jet axis while penetration was the difference in radius from tip to base of the chevron. The effective nozzle diameter $D_{e}$ was determined from the measured mass flow. The vortex strength parameter $\Gamma$ was simply the slope of the chevron edge in the plane normal to the jet diameter. If the chevron edge projected onto the axial plane is given by radius $\mathrm{r}$ as a function of arclength $\mathrm{s}$ at the midpoint of chevron, then the local deflection created by the chevron is proportional to

$$
\Gamma=\left(\frac{\partial r}{\partial s}\right)
$$

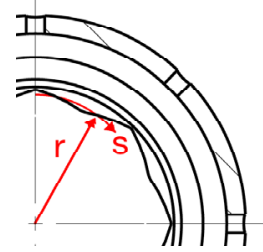

This quantity $\Gamma$ will be referred to as the vortex strength parameter. 
TABLE 1.-PARAMETERS OF CHEVRON NOZZLES TESTED.

\begin{tabular}{|c|c|c|c|c|c|c|}
\hline Nozzle ID & $\mathrm{N}$ & Length $(\mathrm{mm})$ & Angle $\left(^{\circ}\right)$ & Penetration $(\mathrm{mm})$ & $\mathrm{D}_{\mathrm{e}}(\mathrm{mm})$ & $\Gamma$ \\
\hline SMC000 & 0 & & & & 50.8 & 52.2 \\
\hline SMC001 & 6 & 22.6 & 5.0 & 0.985 & 53.6 & 0.089 \\
\hline SMC002 & 4 & 32.0 & 5.0 & 1.395 & 53.9 & 0.089 \\
\hline SMC003 & 10 & 14.0 & 5.0 & 0.609 & 53.6 & 0.089 \\
\hline SMC004 & 5 & 26.6 & 5.0 & 1.160 & 54.5 & 0.000 \\
\hline SMC005 & 6 & 22.6 & 0.0 & -0.005 & 47.7 & 0.292 \\
\hline SMC006 & 6 & 22.6 & 18.2 & 3.525 & 49.9 & 0.297 \\
\hline SMC007 & 6 & 32.0 & 13.3 & 3.681 & 48.4 & 0.288 \\
\hline SMC008 & 10 & 19.3 & 13.0 & 2.175 & 52.6 & $0.489,0.130$ \\
\hline SMC010 & 10 & 15.2 & 9.8 & 1.299 & & \\
\hline
\end{tabular}

In principle, vortices of similar strength will be created keeping the same chevron count and penetration, but varying axial lengths. Similarly, vortices of equal strength could be created for nozzles with different numbers of chevrons by varying penetration to make $\Gamma$ the same.

Further simplifying matters, the chevron nozzles were fabricated by machining blank nozzles with a $5^{\circ}$ taper over the last 0.8 jet diameter $\mathrm{D}_{\mathrm{j}}$. In this tapered section notches were cut using wire electrodischarge machining (EDM) leaving a $30^{\circ}$ bevel at the edges. This created a $5^{\circ}$ penetration angle for whatever chevron pattern was cut. To increase or decrease penetration the chevrons were carefully bent by thinning the nozzle outer diameter near the base of the chevrons and manually bending the chevron to the proper penetration before adding back the removed material with welding rod. The result is a bent chevron which has slight axial curvature ( $2 \mathrm{~cm}$ radius of curvature) at its base.

Determining the throat area of a chevron nozzle is difficult and here the effective diameter $D_{e}$ was determined experimentally by assuming the discharge coefficient to be the same for all nozzles and to use the measured mass flow as a surrogate area measurement. Thus all data presented here have been normalized by this effective nozzle area whose diameter is denoted $\mathrm{D}_{\mathrm{e}}$. While most chevron nozzles that have been measured for thrust have had less penetration than the nozzles studied here, ${ }^{1}$ the anticipated variance in $\mathrm{C}_{\mathrm{fg}}$ is around 1 percent, making the normalization by mass flow the same as normalizing by thrust to within $0.5 \mathrm{~dB}$.

\section{Instrumentation}

Far-field acoustics were measured using pole-mounted 1/4" B\&K 4939 microphones at a $2.54 \mathrm{~m}$ radius from $50^{\circ}$ to $165^{\circ}$ to the jet inlet axis. Data were acquired on microphones simultaneously at $200 \mathrm{kHz}$ sample rate and processed to 40 equivalent jet diameter $\mathrm{D}_{\mathrm{e}}$ distance removing the atmospheric loss for the ambient conditions.

To measure the impact of the chevrons on the flow field plume surveys were conducted using total temperature, total pressure, and static pressure rakes. These rakes consisted of 41 probes of each type on $6.35 \mathrm{~mm}$ centers that were traversed across the flow at exponentially increasing axial locations from 0.1 $\mathrm{D}_{\mathrm{j}}$ to $10 \mathrm{D}_{\mathrm{j}}$. From these measurements mean velocities were estimated.

Some cross-stream stereo particle image velocimetry (PIV) results are presented, primarily to document axial vorticity in the flows. The PIV system was very similar to that described in reference 5. In these tests the seed material for the jet flow was $0.5 \mu \mathrm{m}$ alumina powder dispersed in the flow well upstream of the nozzle using an air-assisted atomizing nozzle to atomize ethanol carrying the particles. The ambient fluid was seeded with $0.2 \mu \mathrm{m}$ oil droplets produced by a commercial 'smoke' generator. Several iterations on ambient seeding arrangements were made, with the final method releasing oil droplet 'smoke' from a commercial fogger that essentially replicated a very low velocity freejet around the research jet. 


\section{Results}

\section{Overall Data}

Flow fields are shown with a broad stroke by plotting the total pressure for cold flow conditions (figure 3) or total temperature for hot flow conditions (figure 4) in cross-stream planes. From these contour plots one obtains a feel for the dramatic changes in jet cross-section that were achieved with the various chevron designs.
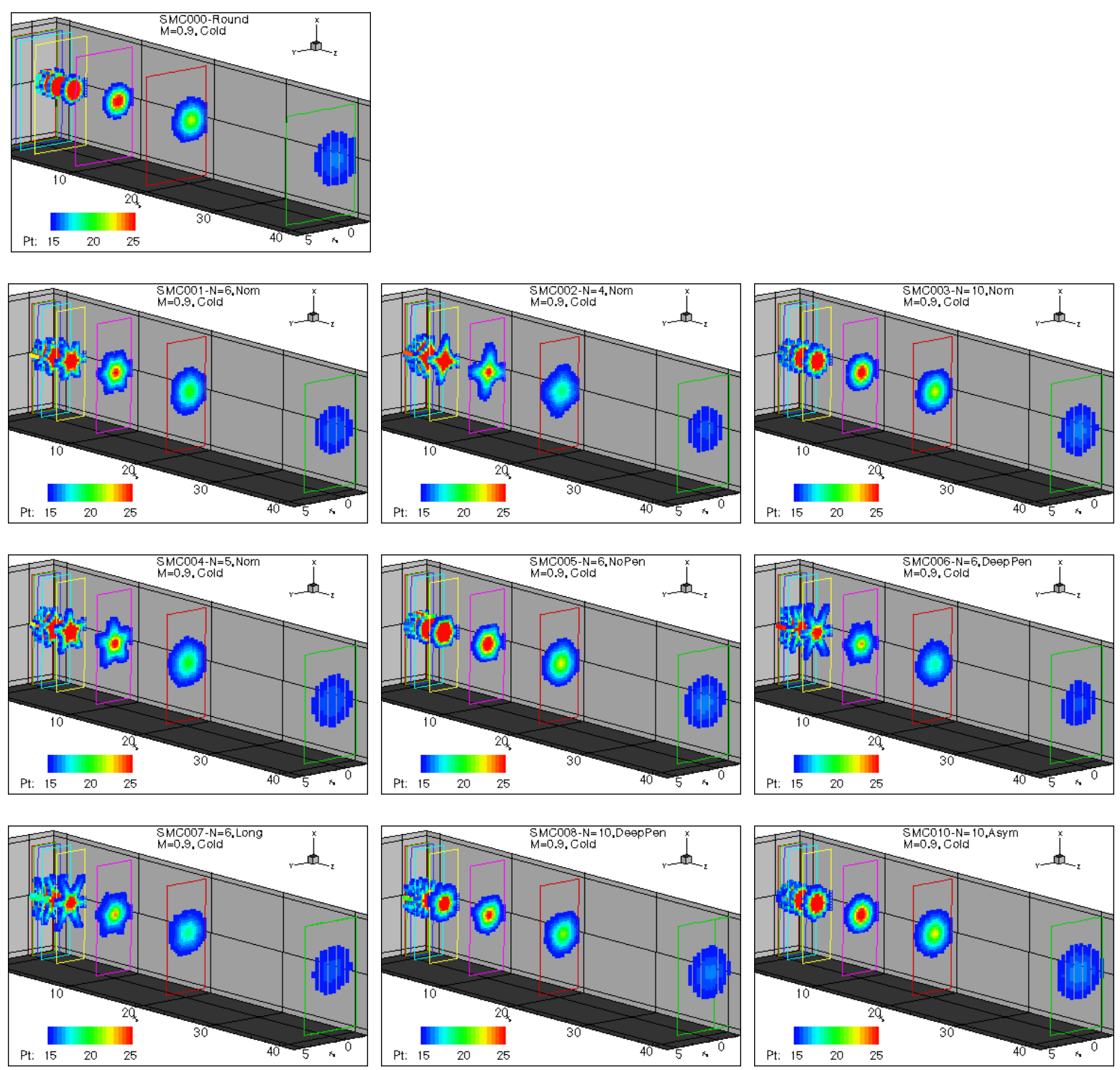

Figure 3.-Total pressure surveys of chevron nozzle jets. Setpoint $7\left(\mathrm{M}_{\infty}=0.9 ; \mathrm{Ts} / \mathrm{T}_{\infty}=0.86\right)$. 

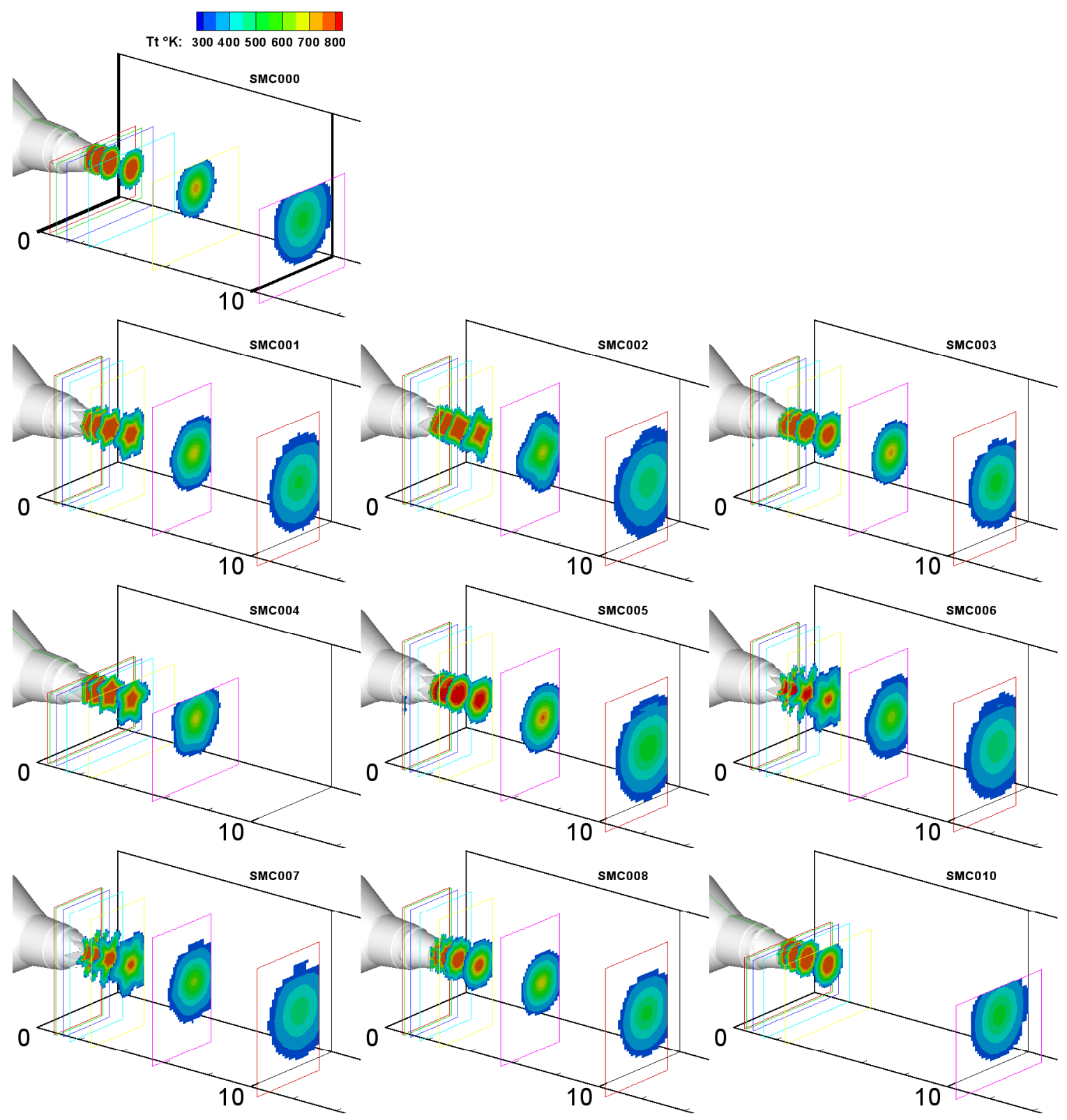

Figure 4. - Total temperature surveys of chevron nozzle jets. Setpoint $46\left(\mathrm{M}_{\infty}=0.9 ; \mathrm{Ts} / \mathrm{T}_{\infty}=2.7\right)$.

Spectral directivity plots for all nozzles are presented in figure 5 for the cold flow, setpoint 7 and in figure 6 for the hot flow, setpoint 46. These are shown as contour plots of SPL as a function of observer angle (measured from the upstream jet axis) and frequency. The frequency $\mathrm{f}$ is scaled to Strouhal number $\left(\mathrm{St}=\mathrm{f} \mathrm{D}_{\mathrm{e}} / \mathrm{U}_{\mathrm{j}}\right)$ and given by one-third octave band numbers (band number $=10 \log _{10}(\mathrm{St})$ ). From these two views of the acoustic far-field spectral directivity one can see the spectral directivity characteristics of the jets and make some judgment how the chevrons change it.

Note that both figures are all plotted on the same SPL scale. Because these two setpoints have the same acoustic Mach number, $\mathrm{M}_{\infty}=0.9$, they have the same peak sound levels, confirming that in jet noise it is the velocity relative to ambient speed of sound that dominates the jet noise scaling. Adding heat to the flow has he effect of sharpening the aft angle peak due to the increased impact of refraction.

Having given these overall pictures of the near-field flow and far-field acoustic impacts of the chevron nozzles, several parametric studies will be presented in more detailed formats. 

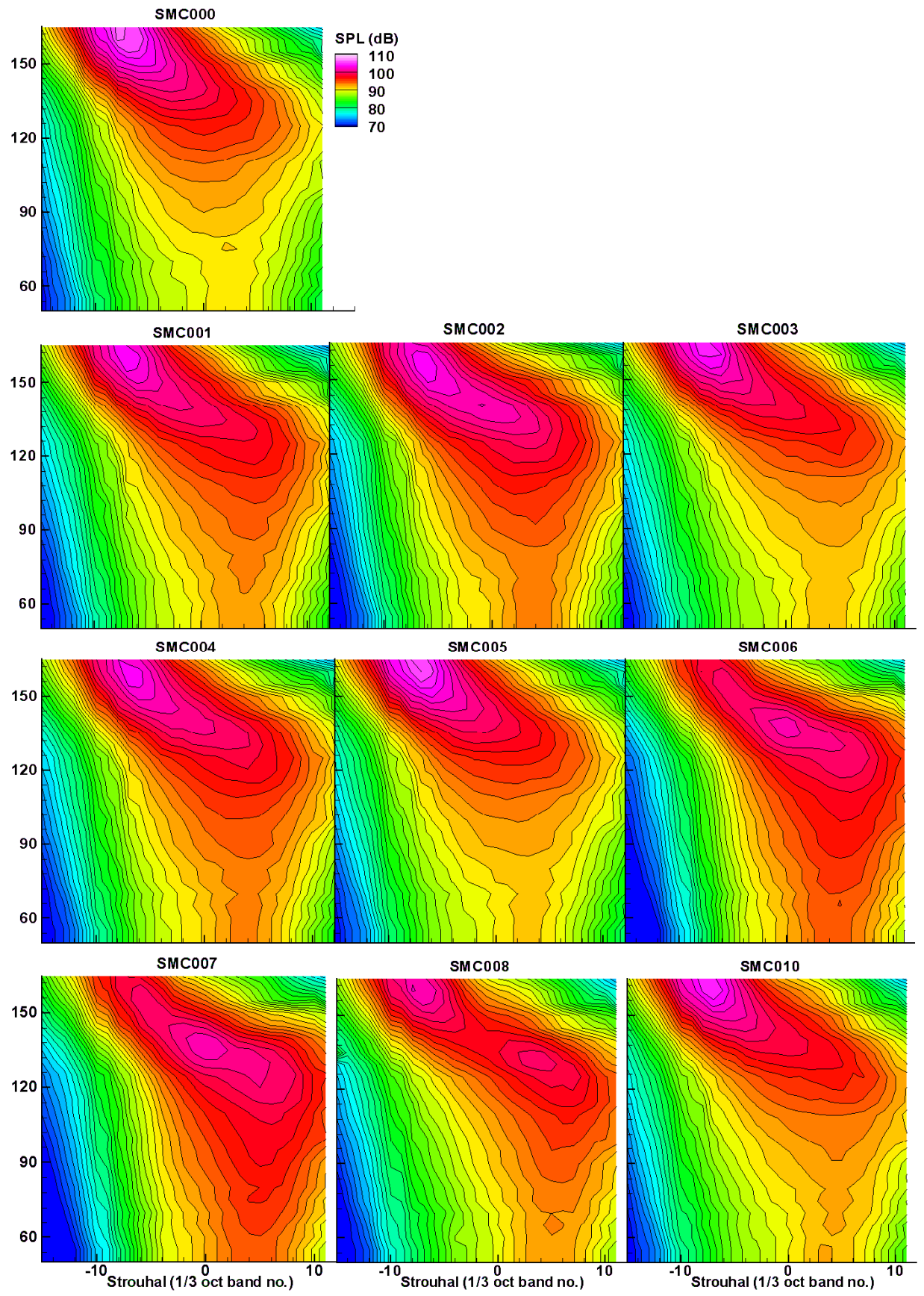

Figure 5.-SPL maps for different chevron configurations at setpoint 7 $\left(M_{\infty}=0.9 ; \mathrm{Ts} / \mathrm{T}_{\infty}=0.86\right)$. Data normalized to 40 equivalent jet diameters, no atmospheric attenuation. 

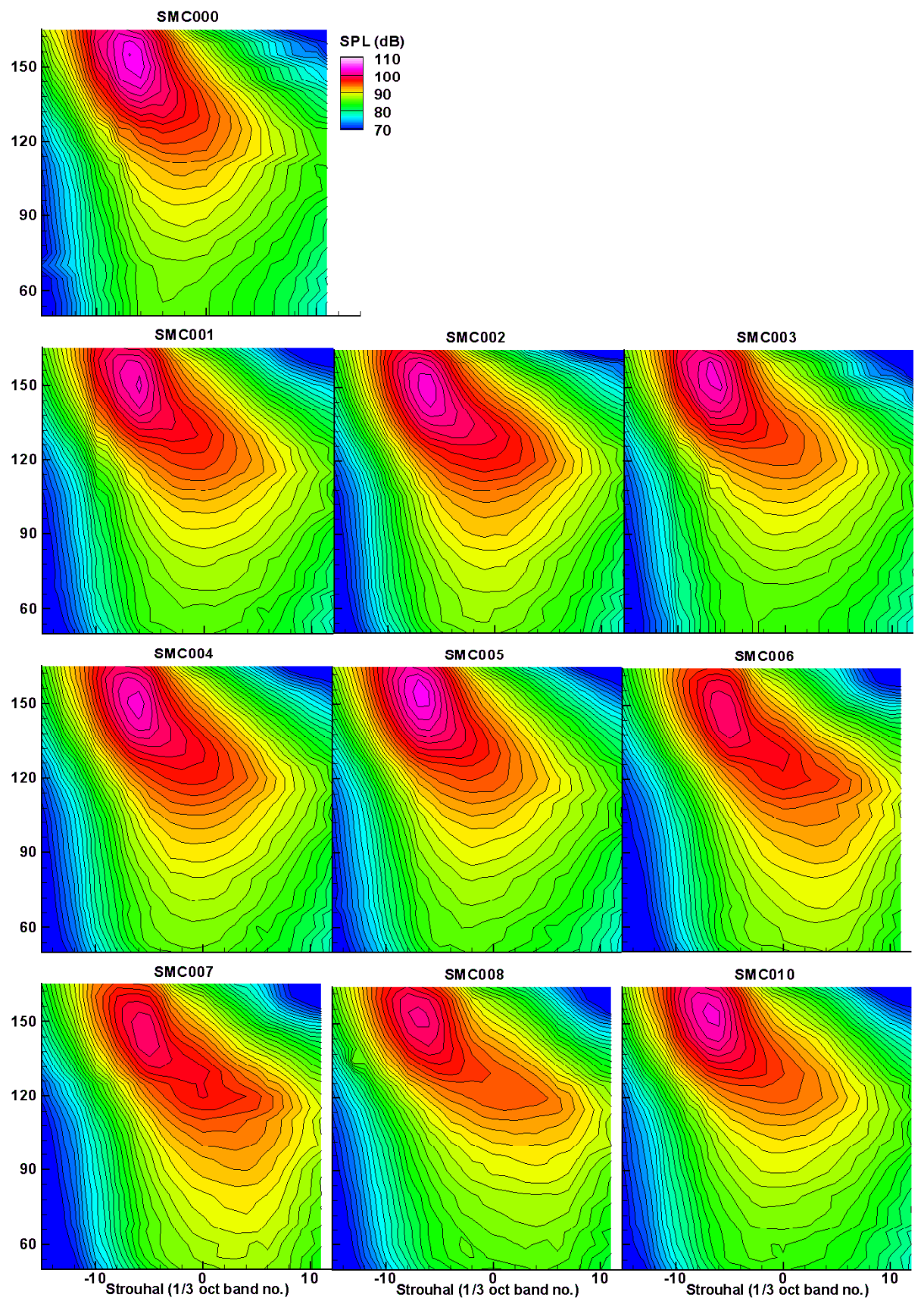

Figure 6.-SPL maps for different chevron configurations at setpoint 46 $\left(\mathrm{M}_{\infty}=0.9 ; \mathrm{Ts} / \mathrm{T}_{\infty}=2.7\right)$. Data normalized to 40 equivalent jet diameters, no atmospheric attenuation. 


\section{Comparisons Defined}

In all, four major comparisons can be made from the data collected.
$\mathrm{C} 1$ : Constant $\mathrm{N}$; varying strength
$\mathrm{C} 2$ : Constant $\mathrm{N}$, varying length
C3: Constant strength; varying $\mathrm{N}$
C4: Constant N, varying symmetry, strength

To more easily quantify differences in the flow fields, the plume survey results were converted to centerline velocity decay. The total pressure, total temperature survey points were used to estimate velocity at different axial stations and the centerline velocity plotted vs axial distance $x / D_{e}$. Note that the axial distance has been scaled by equivalent diameter $\mathrm{D}_{\mathrm{e}}$.

For comparisons of far-field acoustics, the spectra at broadside angles, represented by $90^{\circ}$, and at aft angles, represented by $150^{\circ}$ are shown in line plots. The OASPL directivity provides the connectivity, and in some cases shows the extreme behavior at very large aft angles which characterize the chevron nozzle sound fields. In some cases a direct subtraction of the round jet OASPL from that of the various chevron nozzles is shown to quantify the differences made by the chevrons in both cold and hot flows.

\section{C1: Constant N; Change Strength}

TABLE 2.-CHEVRON NOZZLES AND THEIR PARAMETERS USED TO STUDY EFFECT OF CHEVRON PENETRATION (VORTEX STRENGTH PARAMETER), HOLDING CHEVRON NUMBER AND LENGTH CONSTANT.

\begin{tabular}{|c|c|c|c|c|c|c|}
\hline Nozzle ID & $\mathrm{N}$ & Length $(\mathrm{mm})$ & Angle $\left(^{\circ}\right)$ & $\begin{array}{c}\text { Penetration } \\
(\mathrm{mm})\end{array}$ & $\mathrm{D}_{\mathrm{e}}\left(\mathrm{mm}^{2}\right)$ & $\Gamma$ \\
\hline SMC000 & 0 & & & & 50.8 & \\
\hline SMC005 & 6 & 22.6 & 0.0 & -0.005 & 54.5 & 0.000 \\
\hline SMC001 & 6 & 22.6 & 5.0 & 0.985 & 52.2 & 0.089 \\
\hline SMC006 & 6 & 22.6 & 18.2 & 3.525 & 47.7 & 0.292 \\
\hline
\end{tabular}

Expectations.-For the first comparison, the number of chevrons was held fixed at 6 and the length held at $22.6 \mathrm{~mm}$ while the penetration was varied. This should vary the strength of the vortices, holding vortex spacing constant. This is a classic chevron design problem when optimizing for noise and aero performance.

Flow field.-Jet centerline velocity for both cold and hot setpoints are shown in figure 7 for three 6-chevron nozzles with different penetrations along with the baseline round nozzle. The hot jet had a significantly shorter potential core for all nozzles. Clearly, with increased penetration there was greater centerline decay, with the greatest difference found within the first 10 jet diameters in the cold jet and the first 5 jet diameters in the hot jet. Not too surprisingly, the chevron nozzle with no penetration was insignificantly different from the round jet. Increasing the penetration shows a fairly quick decrease in velocity, but with increasing distance the increased penetration shows diminished impact.

Plots of axial vorticity (figure 8) near the nozzle show the profound impact of chevron penetration on the initial development of the jet shear layer. Clearly defined pairs of counter-rotating vortices produced by the notch between chevrons are evident in the cases with chevron penetration. Interestingly, there is little difference in the axial vorticity after the first 1.5 diameters between high and medium penetration chevrons - the impact is largely made within the first diameter of the jet's development. 
(a)

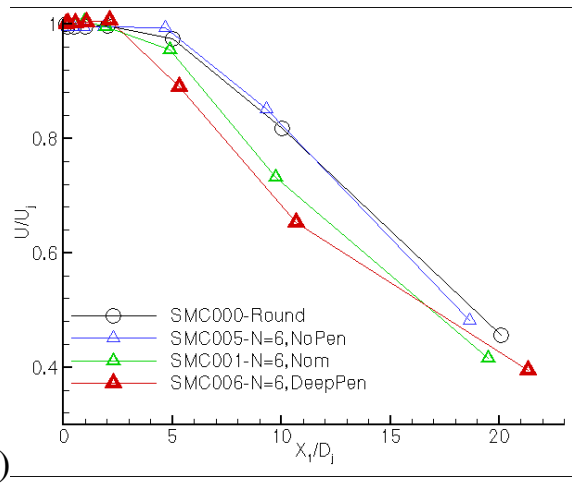

(b)

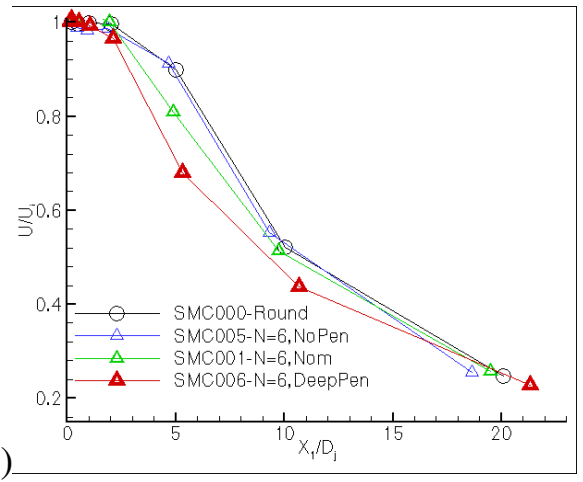

Figure 7.-Centerline velocity decay for 6-chevron nozzles with different penetration. (a) Setpoint 7 (cold), (b) setpoint 46 ( $\mathrm{M}=0.95$, hot).

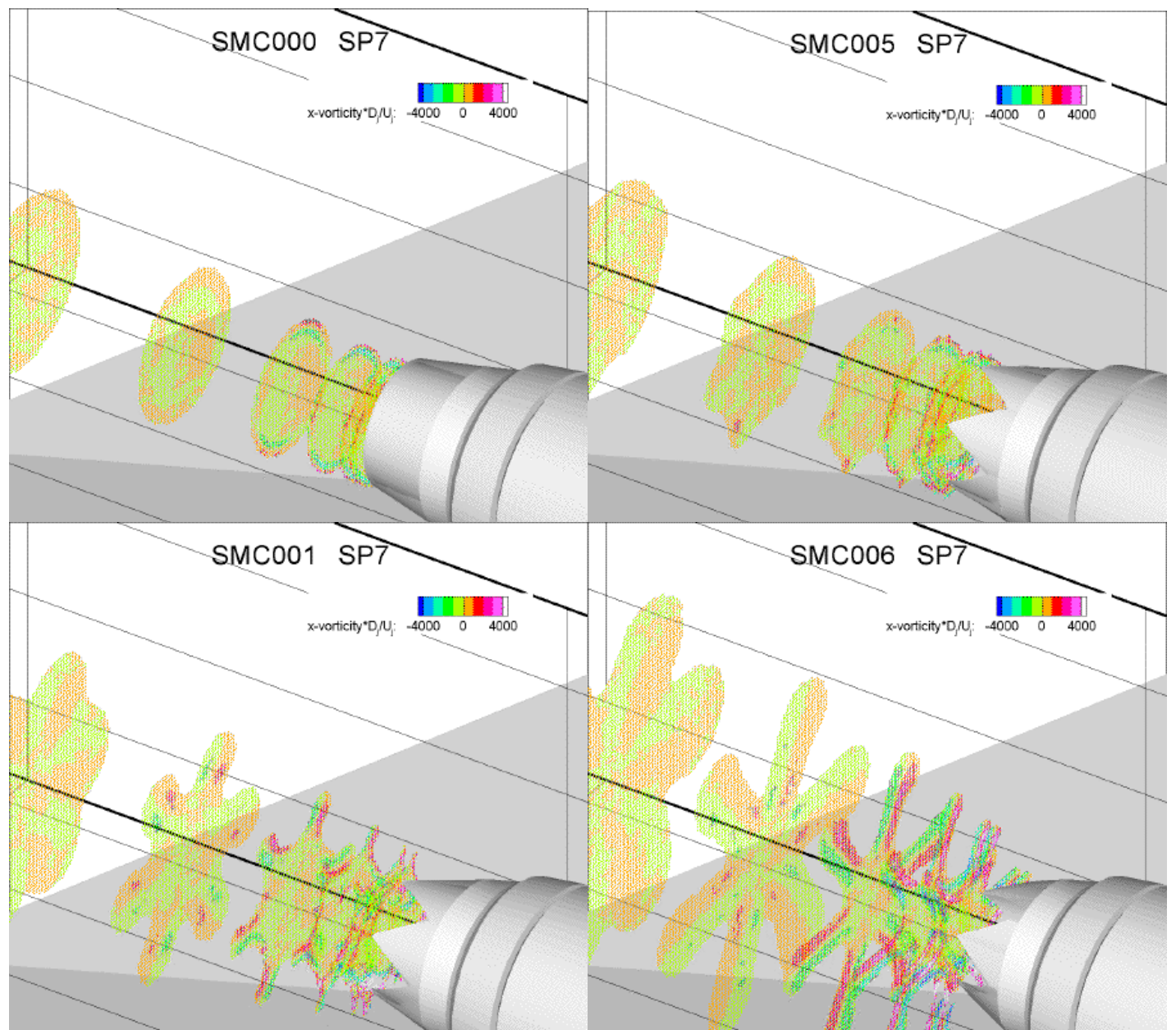

Figure 8.-Axial vorticity near the 6-chevron nozzles with different penetrations, same length.

Acoustic far-field.-Overall, the third octave spectra for the different 6-chevron nozzles in figure 9 show how chevrons, especially ones with rather aggressive penetration such as those used here, significantly reduce low frequency noise and produce more high frequency noise. At $90^{\circ}$ the high frequency increase is $3-5 \mathrm{~dB}$ above the round jet while the low frequency reduction at $150^{\circ}$ is of the same size. The figure also confirms that the no-penetration chevron nozzle (SMC005) was not significantly different from the round jet (SMC0000). 
Although the hot and cold jet spectra differ from each other for each nozzle, the differences between nozzles is consistent from cold to hot. The cross-over point, where the high frequency increase and low frequency reduction meet, shifts toward upstream angles. Higher penetration chevrons deepen the zone of silence, which is already increased by additional refraction from the hot flow. Figure 10 directly compares the impact of the different chevron penetrations, as measured by DOASPL, for the cold (SP7) and hot (SP46) flows. The cold jet shows more increase in noise at broadside angles, and greater noise reduction at the far aft angles.

(a)

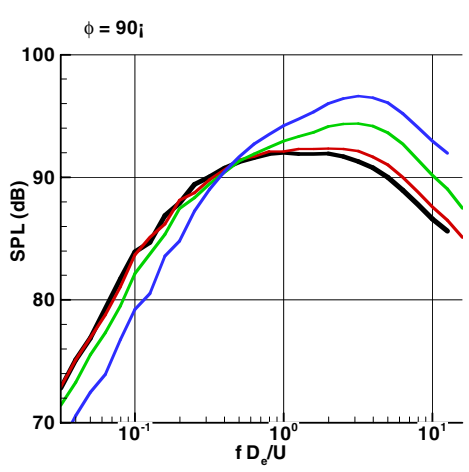

(b)

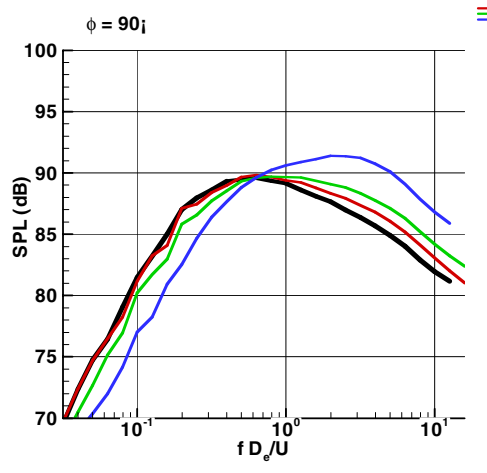

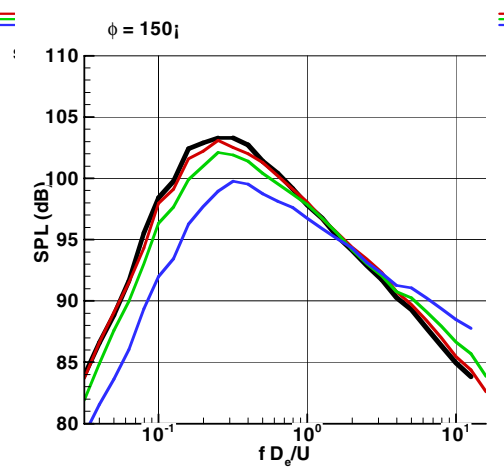

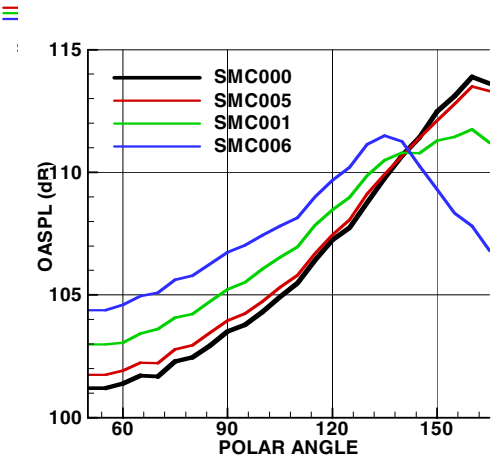

$\equiv$

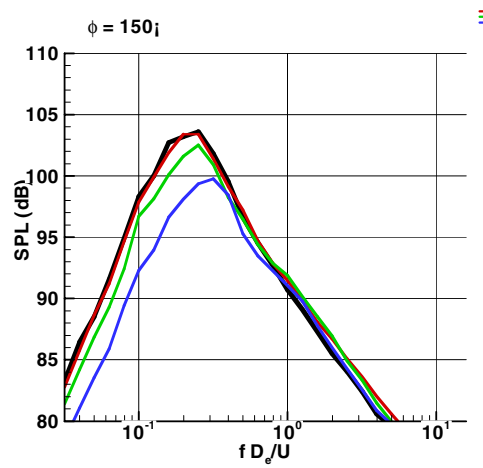

$\equiv$

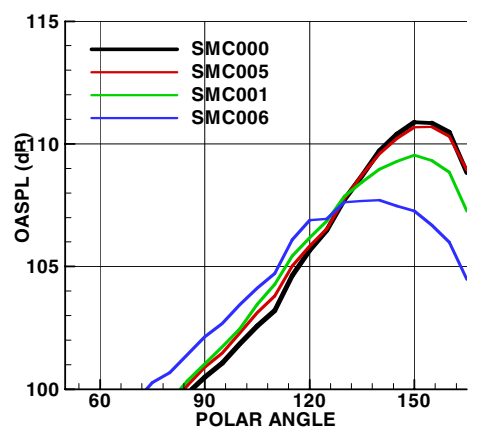

Figure 9.-Far-field acoustics for 6-chevron nozzles with different penetrations. 1/3 octave spectra at emission angles $90^{\circ}$ and $150^{\circ}$, and OASPL. (a) Setpoint 7 (cold), (b) setpoint 46 (hot).

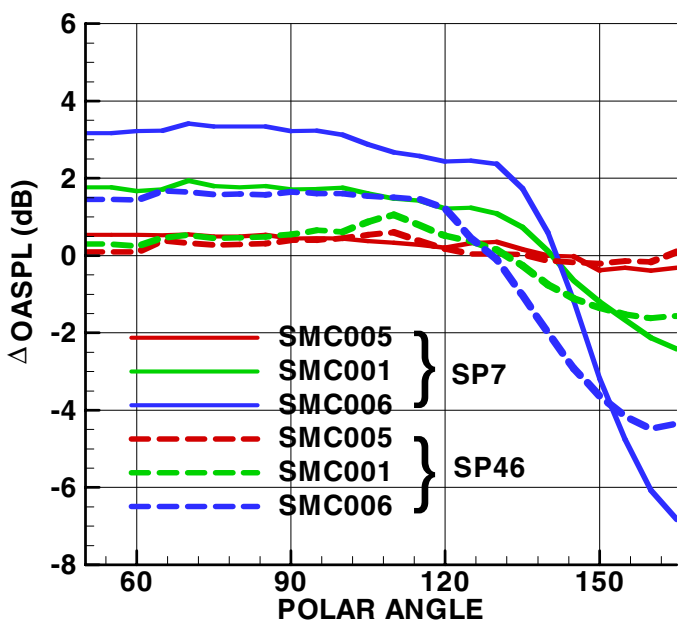

Figure 10.-Difference in OASPL between chevrons and round jet for setpoint 7 (cold) and setpoint 46 (hot). 


\section{C2: Constant N, Varying Length}

TABLE 3.-CHEVRON NOZZLES AND THEIR PARAMETERS USED TO STUDY EFFECT OF CHEVRON LENGTH HOLDING CHEVRON NUMBER AND VORTEX STRENGTH PARAMETER CONSTANT.

\begin{tabular}{|c|c|c|c|c|c|c|}
\hline Nozzle ID & $\mathrm{N}$ & Length $(\mathrm{mm})$ & Angle $\left(^{\circ}\right)$ & $\begin{array}{c}\text { Penetration } \\
(\mathrm{mm})\end{array}$ & $\mathrm{D}_{\mathrm{e}}\left(\mathrm{mm}^{2}\right)$ & $\Gamma$ \\
\hline SMC000 & 0 & & & & 50.8 & \\
\hline SMC006 & 6 & 22.6 & 18.2 & 3.525 & 47.7 & 0.292 \\
\hline SMC007 & 6 & 32.0 & 13.3 & 3.681 & 49.9 & 0.297 \\
\hline
\end{tabular}

Expectations.- This study was where the connection between the vortex strength parameter $\Gamma$ and the initial vorticity field was put to the test. By keeping the $\Gamma$ constant and using length to change penetrations, one could determine whether chevron length was itself an independent parameter or if $\Gamma$ was the significant characteristic.

Flow Field.-In figure 11 the centerline velocity decay shows that the change in chevron length by 40 percent does not greatly change the overall plume. In fact, the measurements of axial vorticity from PIV shown in figure 12 confirm that the axial vorticity is nearly identical when $\Gamma$ is kept constant.

(a)

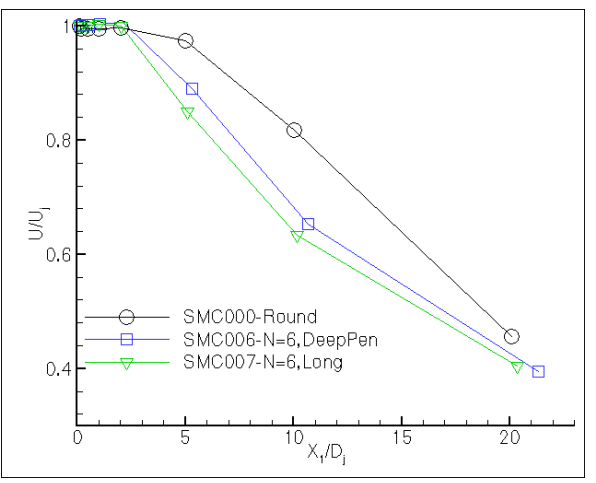

(b)

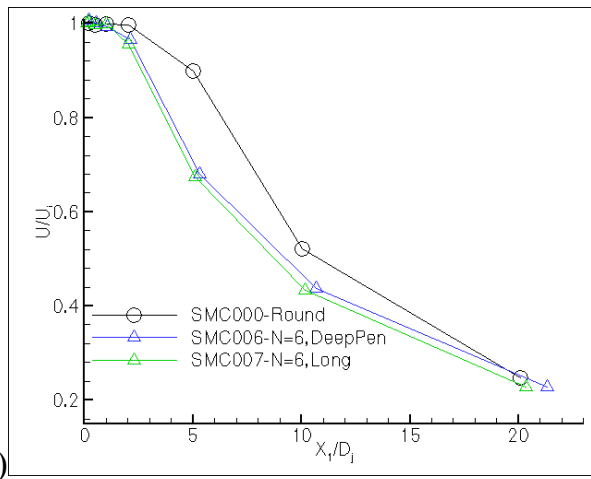

Figure 11.-Centerline velocity decay for 6-chevron nozzles with different lengths, similar vortex strength parameter. (a) Setpoint 7 (cold), (b) setpoint 46 (hot).
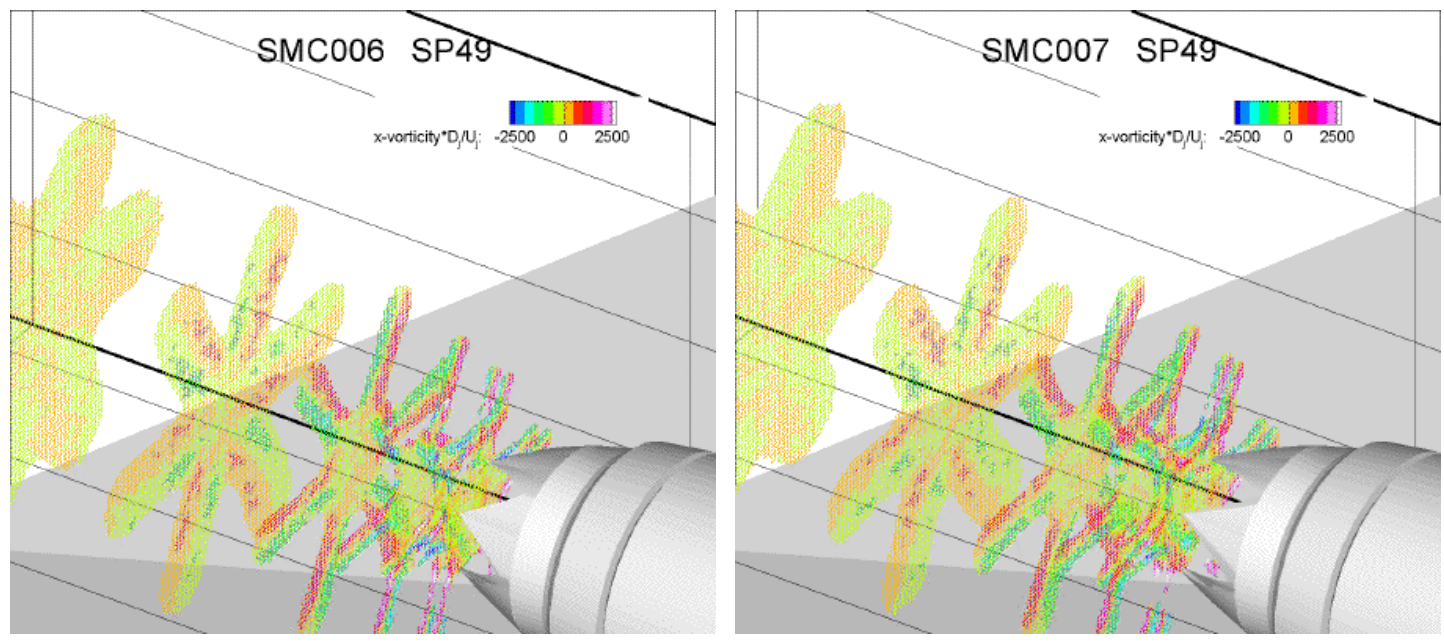

Figure 12.-Axial vorticity near the 6-chevron nozzles with different lengths, same vortex strength parameter. Setpoint 46 (hot). 
Far-field acoustics.-Following the insensitivity of the centerline velocity decay to the change in chevron length, the sound spectra shows similar insensitivity. Even high frequency details are not affected as seen in figure 13 for either cold or hot jets. Once again, the cold jet shows more noise increase at broadside angles for a given chevron geometry than the hot jet (figure 14).

(a)
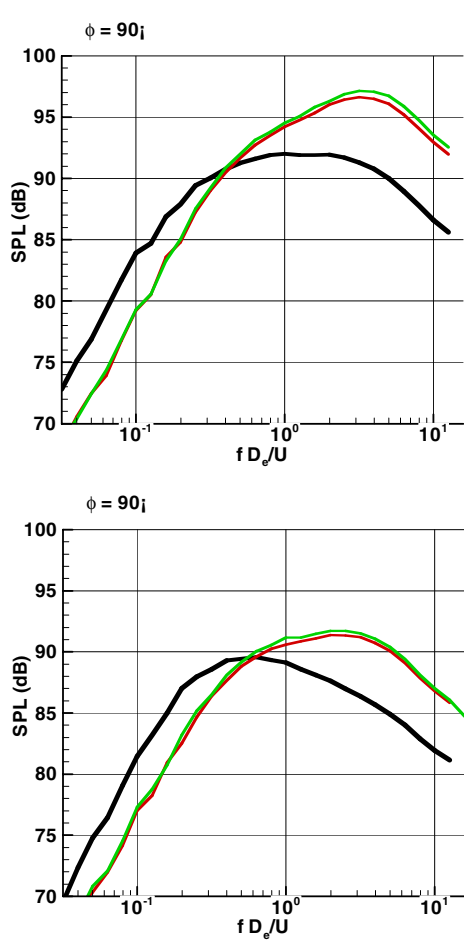
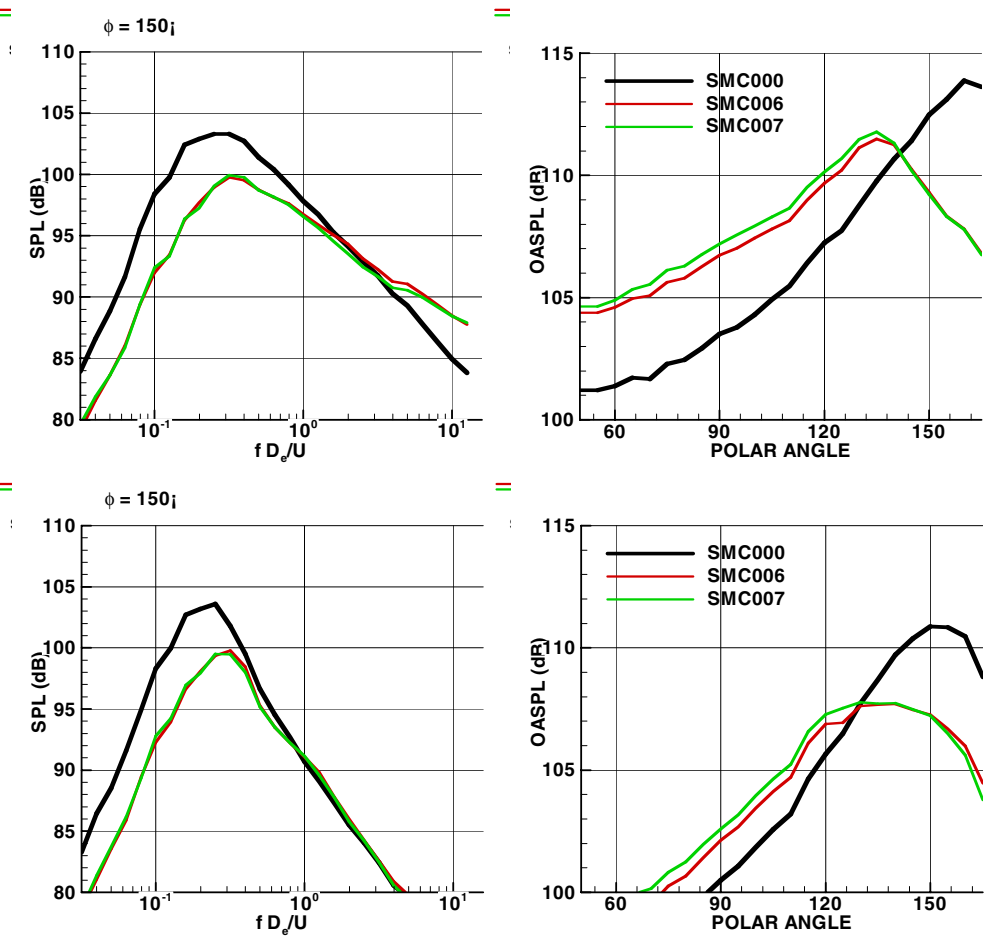

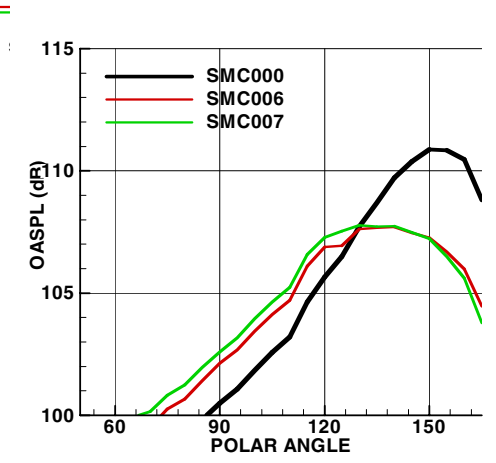

Figure 13.-Far-field acoustics for 6-chevron nozzles with different lengths, similar vortex strength parameter. $1 / 3$ octave spectra at emission angles $90^{\circ}$ and $150^{\circ}$, and

OASPL. (a) Setpoint 7 (cold), (b) setpoint 46 (hot).

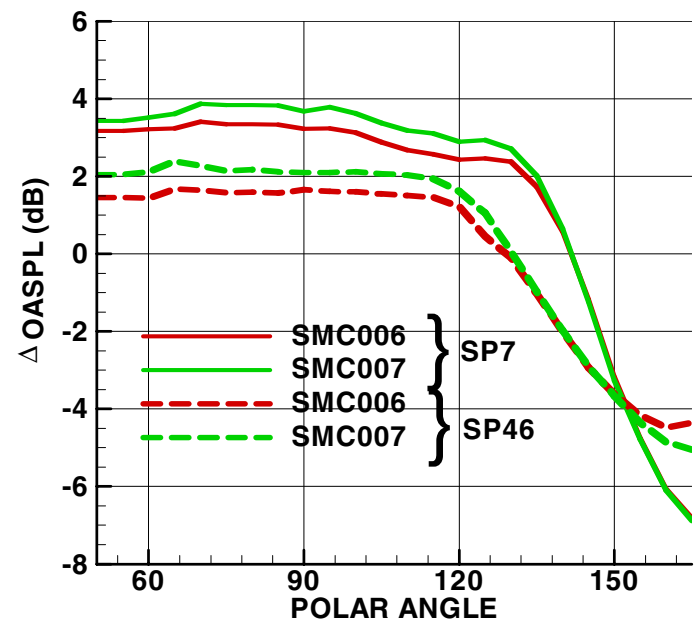

Figure 14.-Difference in OASPL between chevrons and round jet for setpoint 7 (cold) and setpoint 46 (hot). 


\section{C3: Constant Strength; Varying N}

TABLE 4.-CHEVRON NOZZLES AND THEIR PARAMETERS USED TO STUDY EFFECT OF CHEVRON NUMBER N, HOLDING VORTEX STRENGTH PARAMETER CONSTANT.

\begin{tabular}{|c|c|c|c|c|c|c|}
\hline Nozzle ID & $\mathrm{N}$ & Length $(\mathrm{mm})$ & Angle $\left(^{\circ}\right)$ & $\begin{array}{c}\text { Penetration } \\
(\mathrm{mm})\end{array}$ & $\mathrm{D}_{\mathrm{e}}\left(\mathrm{mm}^{2}\right)$ & $\Gamma$ \\
\hline SMC000 & 0 & & & & 50.8 & \\
\hline SMC002 & 4 & 32.0 & 5.0 & 1.395 & 53.6 & 0.089 \\
\hline SMC004 & 5 & 26.6 & 5.0 & 1.160 & 53.6 & 0.089 \\
\hline SMC001 & 6 & 22.6 & 5.0 & 0.985 & 52.2 & 0.089 \\
\hline SMC003 & 10 & 14.0 & 5.0 & 0.609 & 53.9 & 0.089 \\
\hline
\end{tabular}

Expectations.-Given that the vortex strength parameter is held constant for these nozzles, the naive expectation would be that the nozzles would have either some common feature or would monotonically change with vortex spacing. Since varying the number of chevrons mostly affects the spacing of the vortices, the vortices from nozzles with fewer chevrons should not destructively interact.

Flow field.-The expectation that flow characteristics would change smoothly with increasing number of chevrons, while holding vortex strength parameter fixed, was abandoned after viewing the plume survey results, shown in figure 15 . There is a progression in centerline decay where nozzles with fewer chevrons having stronger decay, but the progression was not smooth. The nozzle with $\mathrm{N}=4$ had more decay than the $\mathrm{N}=5$ and 6 for the cold flow, and significantly more than the $\mathrm{N}=10$ nozzle. The $\mathrm{N}=10$ nozzle flow did not significantly deviate from that of the round jet anywhere.

Far-field acoustics.- Similar to the flow field, there was a significant difference between the $\mathrm{N}=4$ (SMC002), 5 (SMC004), and 6 (SMC001) nozzles and $\mathrm{N}=10$ nozzle (SMC003), especially at far aft angles. The main interesting thing to note here was that the $\mathrm{N}=10$ nozzle did not produce significantly more noise at the high frequencies and still produced some noise reduction at aft angles. Although not shown here, the $\mathrm{N}=4$ nozzle has an azimuthal directivity sensitivity, which only shows up at high frequencies at aft angles. Data presented in figure 16 was acquired in the plane of the chevron, which was the quieter orientation.

(a)

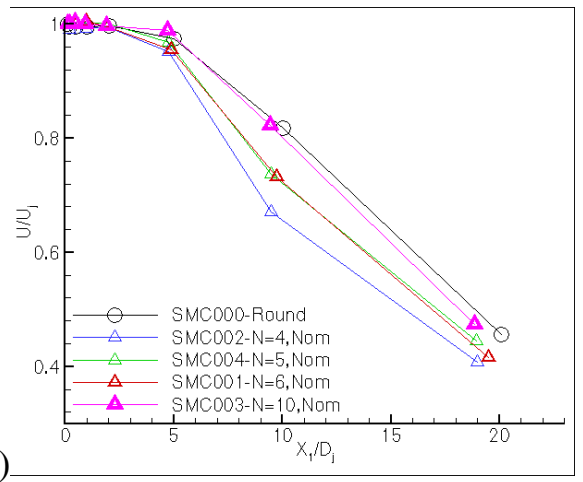

(b)

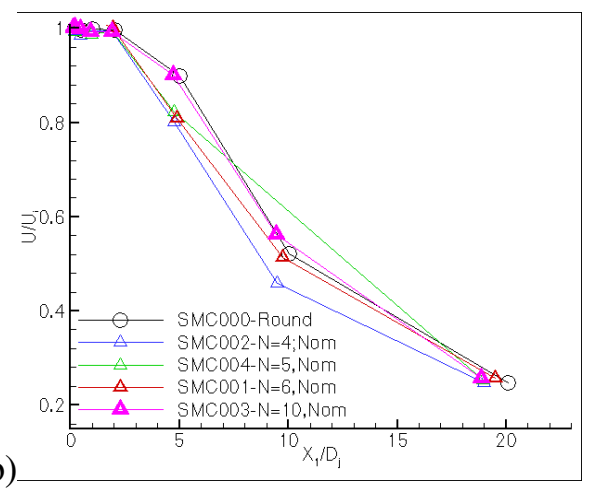

Figure 15.-Centerline velocity decay for chevron nozzles with different chevron count, similar vortex strength parameter. (a) Setpoint 7 (cold), (b) setpoint 46 (hot). 
(a)
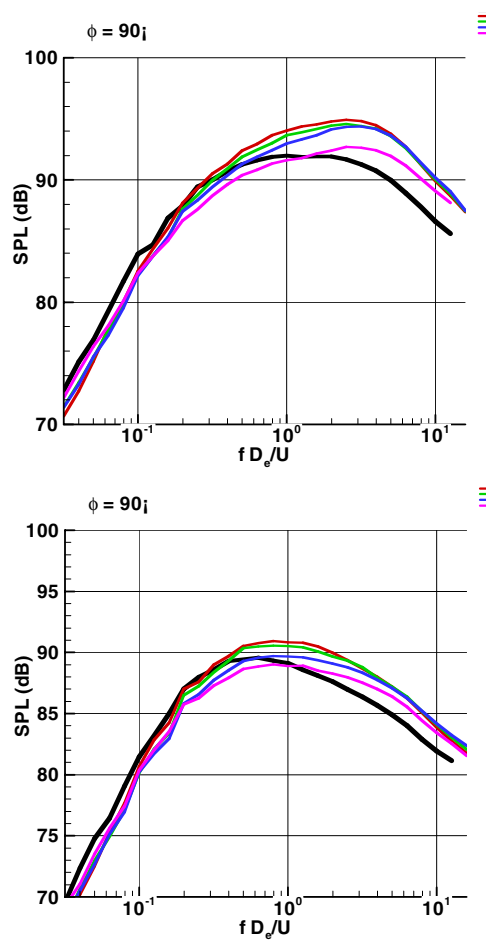
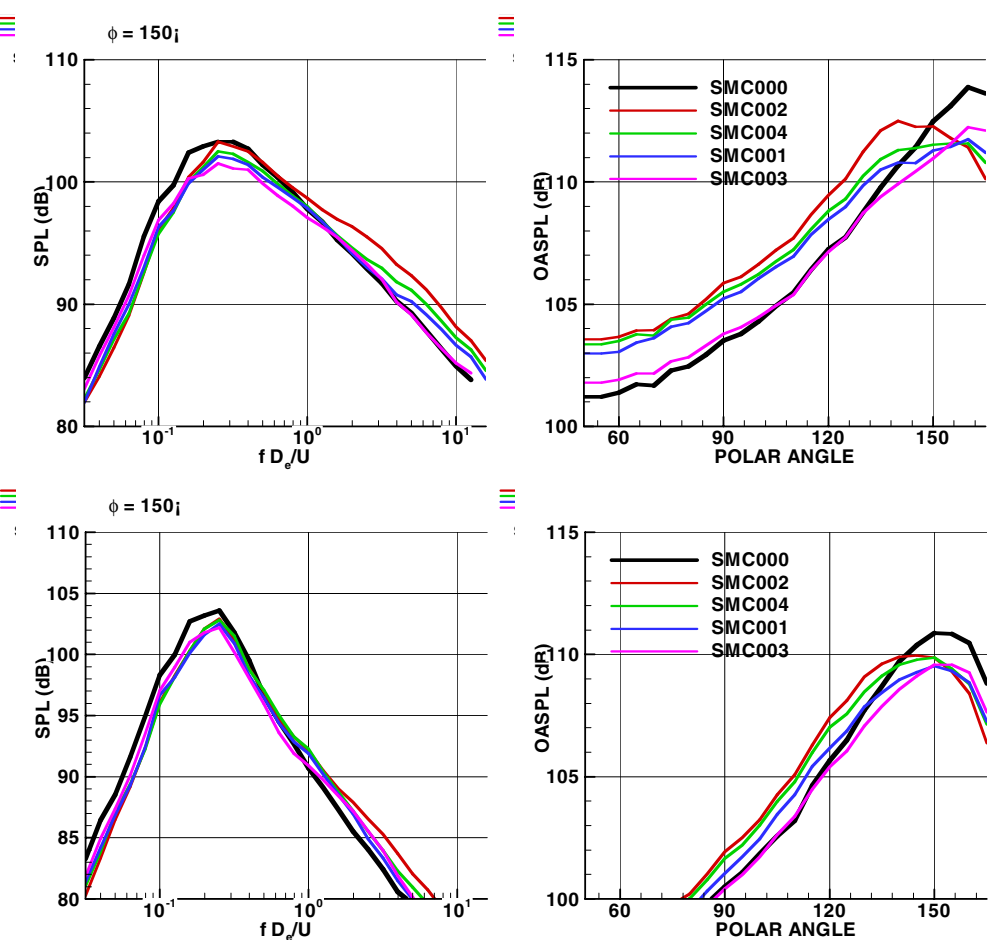

三

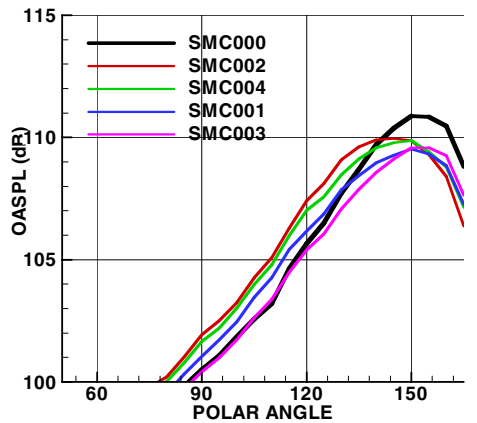

Figure 16.-Far-field acoustics for chevron nozzles with different chevron count, similar vortex strength parameter. $1 / 3$ octave spectra at emission angles $90^{\circ}$ and $150^{\circ}$, and OASPL. (a) Setpoint 7 (cold), (b) setpoint 46 (hot).

\section{C4: Constant N, Varying Symmetry, Strength}

TABLE 5.-CHEVRON NOZZLES AND THEIR PARAMETERS USED TO STUDY EFFECT OF CHEVRON SYMMETRY, HOLDING VORTEX NUMBER N CONSTANT.

\begin{tabular}{|c|c|c|c|c|c|c|}
\hline Nozzle ID & $\mathrm{N}$ & Length $(\mathrm{mm})$ & Angle $\left(^{\circ}\right)$ & $\begin{array}{c}\text { Penetration } \\
(\mathrm{mm})\end{array}$ & $\mathrm{D}_{\mathrm{e}}\left(\mathrm{mm}^{2}\right)$ & $\Gamma$ \\
\hline SMC000 & 0 & & & & 50.8 & \\
\hline SMC003 & 10 & 14.0 & 5.0 & 0.609 & 53.9 & 0.089 \\
\hline SMC010 & 10 & 15.2 & 9.8 & 1.299 & 52.6 & $0.489,0.130$ \\
\hline
\end{tabular}

Expectations. - There was the thought that making the vortex strengths asymmetric would introduce some swirl that could interfere with the formation of large-scale structures and noise. To make the chevron asymmetric, trying to keep the throat area constant, the penetration angle was increased. Unfortunately, the measured mass flow indicates that this was overdone, since it passes less air than the symmetric chevron nozzle. So if anything the asymmetric chevron nozzle should show the effects of higher penetration.

Flow field.-As noted above, the $\mathrm{N}=10$ symmetric chevron nozzle flow field did not deviate significantly from the round jet, at least as measured on the jet centerline. Adding asymmetry to the chevrons did not change this result as seen in figure 17. In fact, given that the asymmetric chevron had greater penetration, the indifference to the asymmetry seems to indicate that asymmetry reduces the effect of the chevrons.

Far-field acoustics.-As expected from flow field results, adding asymmetry to the chevrons had no impact on the far-field sound. The sound fields of the two 10-chevron nozzles in figure 18 are identical within our ability to measure. 
(a)
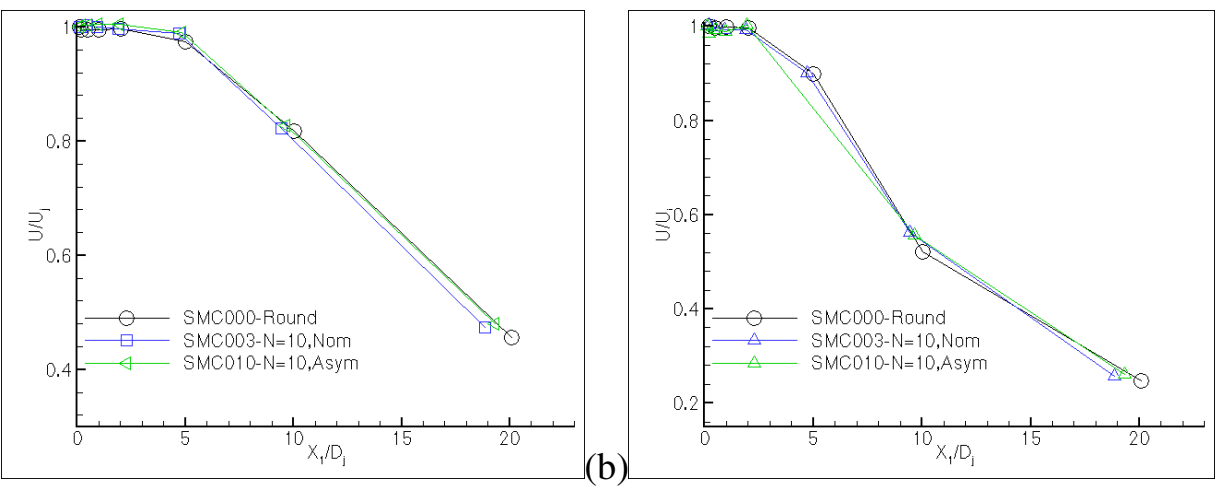

Figure 17.-Centerline velocity decay for 10 -chevron nozzles with symmetric and asymmetric chevrons. (a) Setpoint 7 (cold), (b) setpoint 46 (hot).

(a)
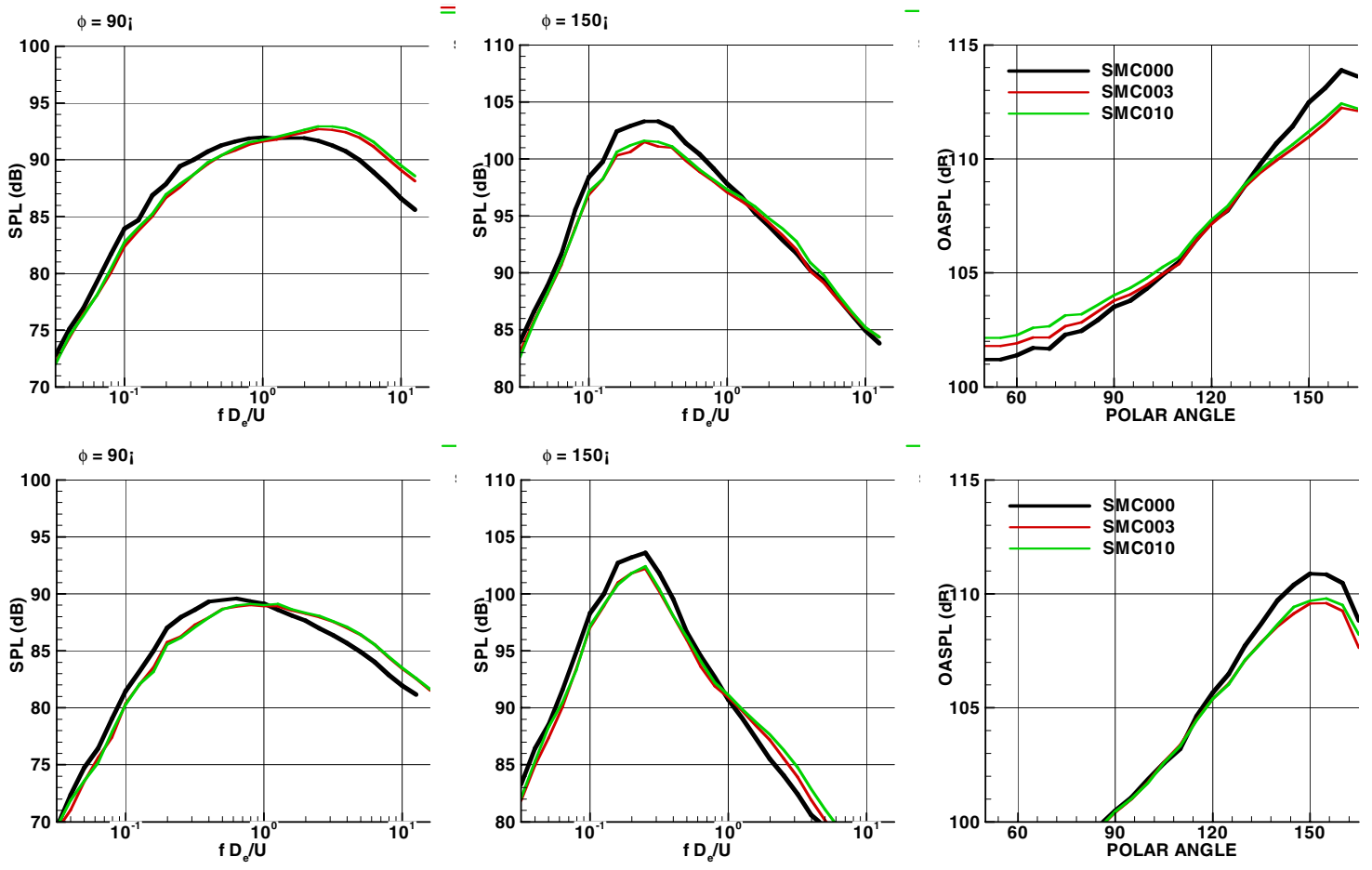

Figure 18.-Far-field acoustics for 10-chevron nozzles with symmetric and asymmetric chevrons. $1 / 3$ octave spectra at emission angles $90^{\circ}$ and $150^{\circ}$, and OASPL.

(a) Setpoint 7 (cold), (b) setpoint 46 (hot).

\section{Conclusion}

A parametric family of hot, single-flow, chevron nozzles has been studied, looking for relationships between chevron geometric parameters, flow characteristics, and far-field noise. Ten models were tested, varying chevron count, penetration, length, and symmetry. Four comparative studies were defined from these datasets. It was found that chevron length was not a major impact on either flow or sound, when chevron count and penetration were kept constant. Chevron penetration has a strong impact on centerline decay and noise, increasing noise at high frequencies and lowering it at low frequencies. Chevron count is 
also a strong player with low frequency reductions being achieved with high chevron counts without high frequency penalty. Chevron asymmetry slightly reduces the impact of the chevron, requiring more penetration for similar impact. Finally, adding heat to the flow reduces the high frequency penalty of the chevrons at broadside angles, and can slightly reduce the benefit found at the far aft angles. However, there were no surprises upon the addition of heat, making studies of chevrons on cold jets reasonable. It still appears that velocity gradients are the most crucial aspect of noise generation in chevron nozzles.

\section{References}

1. Saiyed, N., Mikkelsen, K.L., and Bridges, J., 2000, "Acoustics and Thrust of Separate-Flow Exhaust Nozzles With Mixing Devices for High-Bypass-Ratio Engines," NASA/TM-2000-209948.

2. Bridges, J. \& Wernet, M.P., 2002, "Turbulence Measurements of Separate Flow Nozzles with Mixing Enhancement Features," $8^{\text {th }}$ AIAA/CEAS Aeroacoustics Conference, Breckenridge, CO, (AIAA-2002-2484).

3. Bridges, J. and Wernet, M.P., "Measurements of the Aeroacoustic Sound Source in Hot Jets," $9^{\text {th }}$ AIAA/CEAS Aeroacoustics Conference, Hiltonhead, NC, (AIAA-2003-3130).

4. Tanna, H.K., "The influence of temperature on shock-free supersonic jet noise," J Sound Vibration, vol. 39, 1975

5. Bridges, J. and Wernet, M.P., "Cross-Stream PIV Measurements of Jets with Internal Lobed Mixers," $10^{\mathrm{h}}$ AIAA/CEAS Aeroacoustics Conference, Manchester, UK, (AIAA-2004-2896). 
Public reporting burden for this collection of information is estimated to average 1 hour per response, including the time for reviewing instructions, searching existing data sources, gathering and maintaining the data needed, and completing and reviewing the collection of information. Send comments regarding this burden estimate or any other aspect of this collection of information, including suggestions for reducing this burden, to Washington Headquarters Services, Directorate for Information Operations and Reports, 1215 Jefferson Davis Highway, Suite 1204, Arlington, VA 22202-4302, and to the Office of Management and Budget, Paperwork Reduction Project (0704-0188), Washington, DC 20503.

\begin{tabular}{|l|l|l}
\hline 1. AGENCY USE ONLY (Leave blank) & $\begin{array}{c}\text { 2. REPORT DATE } \\
\text { September } 2004\end{array}$ & $\begin{array}{r}\text { 3. REPORT TYPE AND DATES COVERED } \\
\text { Technical Memorandum }\end{array}$ \\
\hline
\end{tabular}

4. TITLE AND SUBTITLE

5. FUNDING NUMBERS

Parametric Testing of Chevrons on Single Flow Hot Jets

6. AUTHOR(S)

WBS-22-781-30-24

James Bridges and Clifford A. Brown

7. PERFORMING ORGANIZATION NAME(S) AND ADDRESS(ES)

National Aeronautics and Space Administration

John H. Glenn Research Center at Lewis Field

Cleveland, Ohio 44135-3191

8. PERFORMING ORGANIZATION

REPORT NUMBER

E-14582

9. SPONSORING/MONITORING AGENCY NAME(S) AND ADDRESS(ES)

National Aeronautics and Space Administration

Washington, DC 20546-0001

10. SPONSORING/MONITORING

AGENCY REPORT NUMBER

NASA TM-2004-213107

AIAA-2004-2824

\section{SUPPLEMENTARY NOTES}

Prepared for the Tenth Aeroacoustics Conference cosponsored by the American Institute of Aeronautics and Astronautics and the Confederation of European Aerospace Societies, Manchester, United Kingdom, May 10-12, 2004. Responsible person, James Bridges, organization code 5940, 216-433-2693.

12a. DISTRIBUTION/AVAILABILITY STATEMENT

12b. DISTRIBUTION CODE

Unclassified - Unlimited

Subject Categories: 07 and 34

Distribution: Nonstandard

Available electronically at http://gltrs.grc.nasa.gov

This publication is available from the NASA Center for AeroSpace Information, 301-621-0390.

\section{ABSTRACT (Maximum 200 words)}

A parametric family of chevron nozzles have been studied, looking for relationships between chevron geometric parameters, flow characteristics, and far-field noise. Both cold and hot conditions have been run at acoustic Mach number 0.9. Ten models have been tested, varying chevron count, penetration, length, and chevron symmetry. Four comparative studies were defined from these datasets which show: that chevron length is not a major impact on either flow or sound; that chevron penetration increases noise at high frequency and lowers it at low frequency, especially for low chevron counts; that chevron count is a strong player with good low frequency reductions being achieved with high chevron count without strong high frequency penalty; and that chevron asymmetry slightly reduces the impact of the chevron. Finally, it is shown that although the hot jets differ systematically from the cold one, the overall trends with chevron parameters is the same.

\section{SUBJECT TERMS}

Jet flow; Jet exhaust; Flow distribution; Turbulent flow; Azimuth; Noise reduction;

Scalloping; Mixers; Acoustics; Turbulence; Plumes; Jet aircraft noise;

Particle image velocimetry

\begin{tabular}{|c|c|c|}
\hline $\begin{array}{c}\text { 17. SECURITY CLASSIFICATION } \\
\text { OF REPORT } \\
\text { Unclassified }\end{array}$ & $\begin{array}{c}\text { 18. SECURITY CLASSIFICATION } \\
\text { OF THIS PAGE } \\
\text { Unclassified }\end{array}$ & $\begin{array}{c}\text { 19. SECURITY CLASSIFICATION } \\
\text { OF ABSTRACT } \\
\text { Unclassified }\end{array}$ \\
\hline
\end{tabular}

NSN 7540-01-280-5500

15. NUMBER OF PAGES

16. PRICE CODE

20. LIMITATION OF ABSTRACT

Standard Form 298 (Rev. 2-89)

Prescribed by ANSI Std. Z39-18 298-102 

